\title{
POSTERIOR REVERSIBLE ENCEPHALOPATHY SYNDROME
}

\author{
Vinayak Raje1, Pandurang Barve², Manisha Patil ${ }^{3}$, Devdutta Patil ${ }^{4}$, Trishant Chotai ${ }^{5}$
}

${ }^{1}$ MCH, Department of Neurosurgery, Krishna Institute of Medical Sciences, Karad. ${ }^{2}$ Resident, Department of Neurosurgery, Krishna Institute of Medical Sciences, Karad. 3MBBS, TDD, Certified Course in CC Medicine, Krishna Institute of Medical Sciences, Karad. ${ }^{4}$ Resident, Department of Neurosurgery, Krishna Institute of Medical Sciences, Karad. 5Resident, Department of Neurosurgery, Krishna Institute of Medical Sciences, Karad.

\section{ABSTRACT}

\section{BACKGROUND}

Posterior reversible encephalopathy is a proposed clinico-neuroradiological entity characterised by headache, altered mental status, cortical blindness, seizures, other focal neurological signs and a diagnostic magnetic resonance imaging. A variety of different aetiologies have been reported like hypertension, pre-eclampsia/eclampsia, uraemia and porphyria. With early diagnosis and prompt treatment, the syndrome is usually completely reversible. We report a case of PRES in a patient with elevated blood pressure. Clinicians as well as radiologists must be familiar with this clinically frightening, underdiagnosed condition to assure timely diagnosis and treatment to prevent persistent deficits.

\section{KEYWORDS}

PRES, Reversible Encephalopathy, Cortical Blindness.

HOW TO CITE THIS ARTICLE: Raje V, Barve P, Patil M, et al. Posterior reversible encephalopathy syndrome. J. Evolution Med. Dent. Sci. 2016;5(96):7094-7095, DOI: 10.14260/jemds/2016/1605

\section{BACKGROUND}

Posterior Reversible Encephalopathy Syndrome (PRES) is a proposed clinico-neuroradiological entity with a vast spectrum of different aetiologies. The clinical hallmark of this syndrome are headache, confusion, seizures, cortical visual disturbances or blindness and less common are other focal neurological signs. A variety of causes are known like hypertension, pre-eclampsia/eclampsia, uraemia and porphyria. We report a patient of PRES in whom Blood Pressure (BP) was elevated and no other aetiology of PRES could be unfolded.

\section{CASE REPORT}

A 17-year-male admitted with chief complaints of one episode of generalised tonic-clonic convulsion. Patient has history of headache since 3 days. On admission patient was drowsy, arousable and obeying commands. His pulse was $110 / \mathrm{min}$ and blood pressure was $160 / 100 \mathrm{mmHg}$. Patient do not have any history of being medically treated for hypertension previously. Patient was investigated with abdominal sonography to rule out renal artery stenosis and pheochromocytoma as the cause of persistent hypertension in this age group, 24-hour urinary Vanillylmandelic Acid (VMA) was sent and it was normal. Blood pressure was measured manually thrice a day and was persistently raised with the highest measurements of $170 / 110 \mathrm{mmHg}$. Echocardiography was normal. Magnetic Resonance Imaging (MRI) scan revealed high signal intensities on T2 weighted images, which were pronounced in the parieto-occipital cortices in the both hemispheres. The Electroencephalogram

Financial or Other, Competing Interest: None.

Submission 19-09-2016, Peer Review 20-11-2016,

Acceptance 26-11-2016, Published 01-12-2016.

Corresponding Author:

Dr. Pandurang Barve,

Resident, Department of Neurosurgery,

Krishna Institute of Medical Sciences, Karad.

E-mail: pandurangexams@gmail.com

DOI: $10.14260 /$ jemds $/ 2016 / 1605$

\section{(c) $(i) \risingdotseq$}

(EEG) was done, which was suggestive of ongoing seizure disorder. The patient improved neurologically over a period of 4 days and his blood pressure settled to $140 / 80 \mathrm{mmHg}$ with antihypertensives.

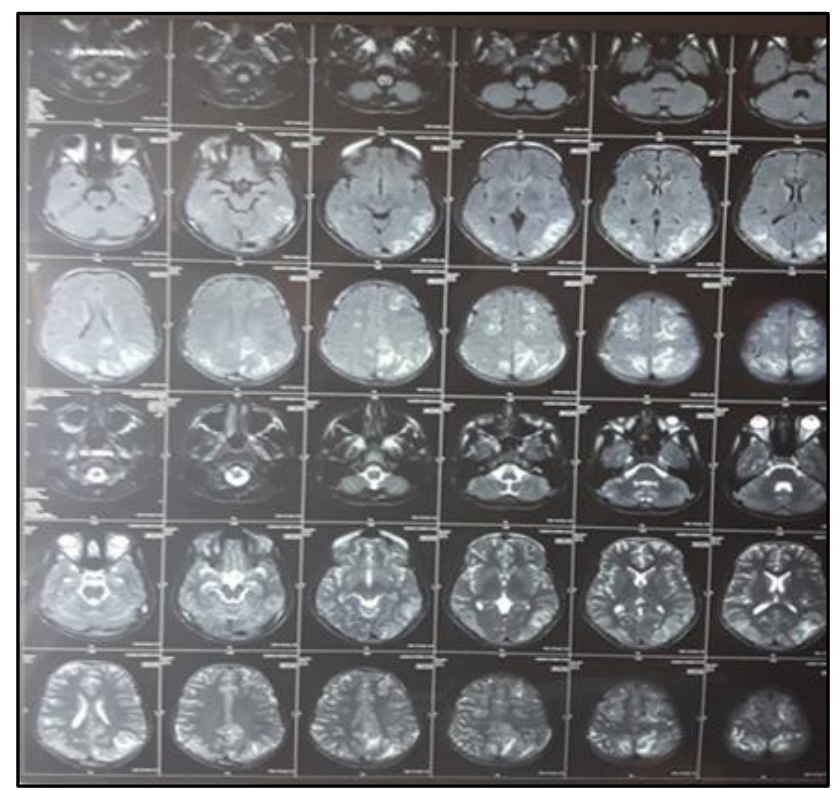

Figure 1. High Signal Intensities on T2 Weighted Images, which were Pronounced in the

Parieto-Occipital Cortices in the both Hemispheres

\section{DISCUSSION}

PRES can be diagnosed with (massive) reversible hyperintensities on T2-weighted cranial MR-images. Predominantly, it affects the territory of the posterior circulation and the clinical hallmarks are headache, vomiting, confusion, seizures, cortical visual disturbances or blindness and less common are other focal neurological signs.1,2,3 Modern imaging modalities (Diffusion Weighted Imaging (DWI) with apparent diffusion coefficients (ADC-maps) could prove that most cases of PRES are caused by vasogenic oedema rather than cytotoxic oedema. 4,5 The pathogenesis is 
attributed to a failure of cerebral autoregulation that probably is facilitated in posterior brain regions due to a sparse sympathetic innervation of the vertebrobasilar vascular system..$^{4,6}$ Isolated brainstem involvement is rare, but has even been reported as a clinically silent reversible phenomenon.7,8,9 In any case, the absence of abnormalities on DWI (with increased ADC) can be interpreted as a favourable prognostic finding, whereas increased signal on DWI or reduced ADC point towards frank ischaemia with cytotoxicity and cell loss. ${ }^{10}$

The cause of PRES remains controversial, but the most popular theory is that severe hypertension causes interruption to brain autoregulation. ${ }^{11}$ Cerebral blood flow is usually regulated by dilatation and constriction of vessels to maintain adequate tissue perfusion 11 and to simultaneously avoid excessive intracerebral hypertension. Breakdown in autoregulation occurs above a mean arterial blood pressure of $150-160 \mathrm{mmHg}$ in chronic hypertension, it occurs at higher pressures. ${ }^{11}$ Uncontrolled hypertension leads to hyperperfusion and cerebral vessel damage resulting in interstitial extravasation of proteins and fluids causing vasogenic oedema. Irreversible damage is seen at mean arterial pressure above $200 \mathrm{mmHg} .{ }^{11}$

The key to diagnosis in PRES naturally is the Magnetic Resonance Imaging (MRI), but suspicion must be raised by the clinician who should be familiar with this underdiagnosed, clinically frightening syndrome to avoid persistent deficits.10,12 It mostly is a benign, reversible condition, especially once the causative factor (eg. hypertension) is eliminated.

\section{REFERENCES}

1. Casey SO, Sampaio RC, Michel E, et al. Posterior reversible encephalopathy syndrome: utility of fluidattenuated inversion recovery MR imaging in the detection of cortical and subcortical lesions. Am J Neuroradiol 2000;21(7):1199-206.

2. Hinchey J, Chaves C, Appignani B, et al. A reversible posterior leukoencephalopathy syndrome. N Engl J Med 1996;334(8):494-500.
3. Schwartz RB, Feske SK, Polak JF, et al. Preeclampsiaeclampsia: clinical and neuroradiographic correlates and insights into the pathogenesis of hypertensive encephalopathy. Radiology 2000;217(2):371-6.

4. Schwartz RB, Mulkern RV, Gudbjartsson $\mathrm{H}$, et al. Diffusion-weighted MR imaging in hypertensive encephalopathy: clues to pathogenesis. Am J Neuroradiol 1998;19(5):859-62.

5. Ay H, Buonanno FS, Schaefer PW, et al. Posterior leukoencephalopathy without severe hypertension: utility of diffusion-weighted MRI. Neurology 1998;51(5):1369-76.

6. Edvinsson L, Owman C, Sjoberg NO. Autonomic nerves, mast cells, and amine receptors in human brain vessels. A histochemical and pharmacological study. Brain Res 1976;115(3):377-93.

7. Casey SO, Truwit CL. Pontine reversible edema: a newly recognized imaging variant of hypertensive encephalopathy? Am J Neuroradiol 2000;21(2):243-5.

8. Chang GY, Keane JR. Hypertensive brainstem encephalopathy: three cases presenting with severe brainstem edema. Neurology 1999;53(3):652-4.

9. Morello F, Marino A, Cigolini M, et al. Hypertensive brain stem encephalopathy: clinically silent massive edema of the pons. Neurol Sci 2001;22(4):317-20.

10. Truwit CL, Denaro CP, Lake JR, et al. MR imaging of reversible cyclosporine A-induced neurotoxicity. Am J Neuroradiol 1991;12(4):651-9.

11. Bartynski WS. Posterior reversible encephalopathy syndrome, part 2: controversies surrounding pathophysiology of vasogenicedema. AJNR Am J Neuroradiol 2008;29:1043-9.

12. Utz N, Kinkel B, Hedde JP, et al. MR imaging of acute intermittent porphyria mimicking reversible posterior leukoencephalopathy syndrome. Neuroradiology 2001;43(12):1059-62. 